\title{
Binocular Amsler's charts
}

\author{
J. LANG
}

University Eye Clinic, Zürich, Switzerland

Amsler's charts have long proved to be very useful for detecting organic macular and $\overrightarrow{0}$ paramacular disorders. The chart consists of a grid of lines with a central fixation dot, $\vec{\omega}$ the whole chart at $30 \mathrm{~cm}$. distance subtending an angle of $20^{\circ}$ (Amsler, 1949).

In the examination of functional amblyopia, we have found that the use of an Amslero․ㅡ. chart can be very helpful in understanding the difference between anisometropic amblyopia and the amblyopia of microtropia. In amblyopia ex anisometropia a central scotoma is almost always indicated by the patient, whereas in microtropic amblyopia with central fixation the scotoma is as a rule paracentral and on the temporal side. The Amsler charto with red lines has proved to be more sensitive than that with white ones. The patient $\rightarrow$ must always be asked to compare the amblyopic eye with the good eye.

The functional scotomata are of course not as clearly described as organic scotomata. The lines are not usually completely extinguished in certain areas, but become inter- $\vec{\theta}$ mittently hazy. Attention must be paid to the fact that fixation should not be shifted.away from the central spot.

To extend this uniocular examination into a binocular examination, we have used Amsler's charts with polarized projection. A slide with a complete Amsler's chart is seen with the amblyopic eye, whereas only the outer lines and the fixation dot are seen with $\stackrel{\varrho}{\varrho}$ the normal eye. With binocular vision, the scotomata are larger and more discernible. $\overrightarrow{\vec{\prime}}$ In amblyopia ex anisometropia a central scotoma is again found (Fig. I). In severe 3 microtropic amblyopia, the Amsler's chart is suppressed. In slight microtropic amblyopia with central fixation, the scotoma is again found to be on the temporal side, but with binocular vision it extends over the middle, the nasal side being usually unaffected (Fig. 2).응 This is understood to be a fixation point scotoma, not a central scotoma.

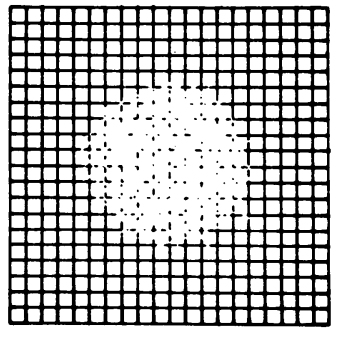

FIG. I Central scotoma in anisometropic amblyopia

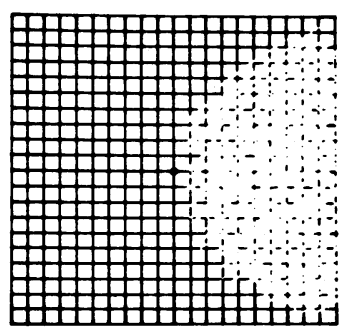

FIG. 2 Paracentral scotoma in right microtropic amblyopia

The same results are obtained with Amsler's charts used on the synoptophore. Here $\frac{\mathbb{\Phi}}{\widetilde{\Phi}}$ again, a complete Amsler's chart is put before the amblyopic eye whereas only the outer 

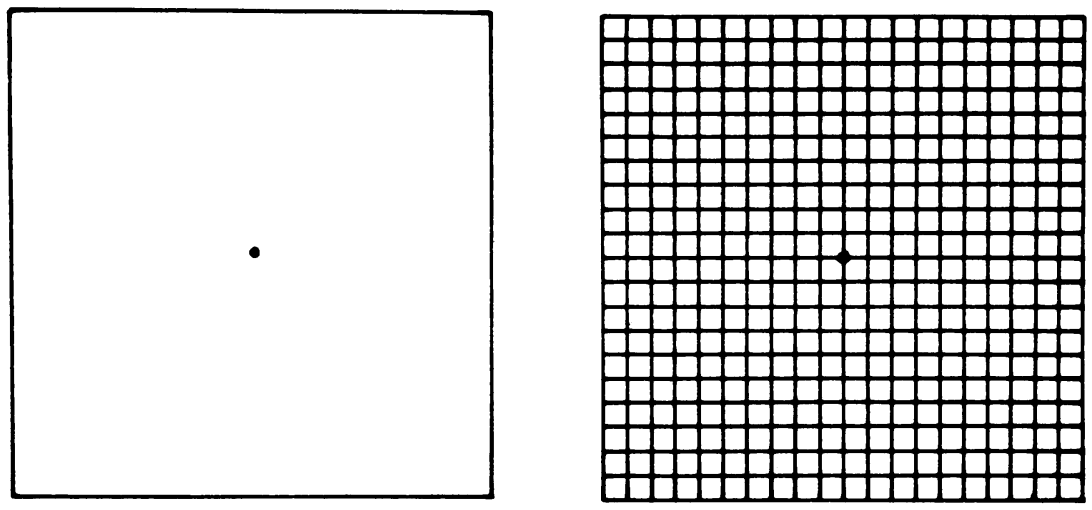

FI G. 3 Slides for binocular Amsler's chart

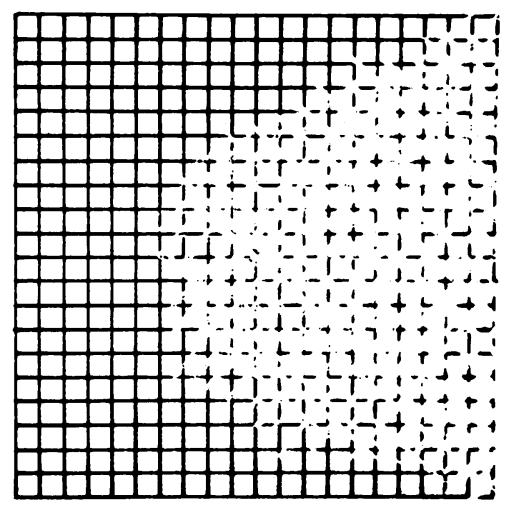

FIG. 4 Scotoma of right microtropia in binocular vision

lines and the fixation dot are seen by the normal eye (Fig. 3). For the synoptophore, the charts have to be reduced in size, subtending an angle of only $10^{\circ}$ instead of $20^{\circ}$. The use of these binocular charts on the synoptophore has become part of the routine examination in our practice in these cases. It proves especially informative when the gap in the light streak with striated lenses is not seen. By this simple means a rapid diagnosis of suppression areas can be made and central, paracentral, and fixation point scotomata can be differentiated (Fig. 4).

\section{Summary}

Binocular Amsler's charts are proposed for detecting functional scotomata in binocular vision.

\section{References}

AmsLer, м. (1949) Trans. ophthal. Soc. U.K., 69, 397

LANG, J. (1969) Brit. orthopt. F., 26, 30

- (1970) "Strabismus '69: Transactions of the Consilium Europaeum Strabismi Studio Deditum Congress, London, September, 1969”, p. ı6o. Kimpton, London 